Available online on 15.05.2019 at http://ujpr.org
Universal Journal of Pharmaceutical Research
An International Peer Reviewed Journal
Open access to Pharmaceutical research

\title{
CAUSES FOR EXTRACTION OF PERMANENT TEETH IN GENERAL DENTAL PRACTICES IN YEMEN

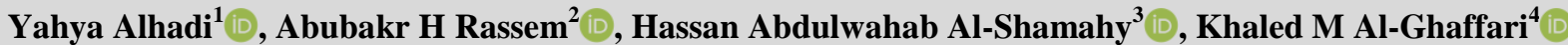 \\ ${ }^{1}$ Department of Oral and Maxillo-Facial Surgery, Faculty of Dentistry, Sana'a University, Republic of Yemen. \\ ${ }^{2}$ Department of Oral and Maxillo-Facial Surgery, Faculty of Dentistry, Hodeidah University, Republic of Yemen. \\ ${ }^{3}$ Departement of Basic Sciences, Faculty of Dentistry, Sana'a University, Republic of Yemen. \\ ${ }^{4}$ Department of Conservative Dentistry and Oral Health, Faculty of Dentistry, Sana' a University, Republic of Yemen.
}

\section{ABSTRACT}

Objective: The aim of this survey was to investigate the primary causes for extraction of permanent teeth, its correlations with age and gender, as well as identify the important predictors for dental caries in Sana'a University dental clinics in Sana'a city, Yemen. Methods: The study was conducted over a period of one year; its population consisted of 1,420 patients, aged 9-72 years, who underwent tooth extraction. There were 761(53.6\%) male and $659(46.4 \%)$ female patients. The frequency distribution was calculated using the t-test, ANOVA and t test for differences in mean number of extracted teeth and the logistic regression model to evaluate the variables associated with causes for tooth extraction.

Results: A total of 2,585 teeth were extracted from the 1,420 patients. The highest rate $(23.1 \%)$ of extraction occurred for those 41-50 years old. Males comprised 53.6\% of patients but had more teeth $(1598,61.8 \%)$ extracted than females $(987,38.2 \%)$. The rate of teeth extracted on the day of the survey per patient was $1.82 \pm 0.07$ ( $2.1 \pm 0.1$ in males and $1.5 \pm 0.05$ in females). Tooth loss due to caries was $69 \%$; periodontal disease was $28 \%$; pre-prosthetic reasons were $1.9 \%$ and other reasons were $1.14 \%$. There was a significant association between patient characteristics (age and gender) and number of teeth extracted in which the Mean \pm SD of extracted numbers were increase with increasing age and higher in male patients than in females $(p<0.001)$. The most frequently extracted teeth were mandibular first and second molars $(446,17.3 \%)$, followed by maxillary premolars $(415,16.1 \%)$, while mandibular canines were least frequently extracted $(87,3.4 \%)$.

Conclusion: In conclusion; dental caries and periodontal problems were the main causes for tooth extraction in Sana'a city, Yemen. Keywords: Dental caries, periodontal disease, tooth extraction, Yemen.

Article Info: Received 3 March 2019; Revised 7 April; Accepted 5 May, Available online 15 May 2019

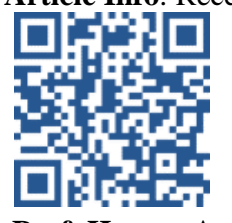

Cite this article-

Alhadi Y, Rassem AH, Al-Shamahy HA, Al-Ghaffari KM. Causes for extraction of permanent teeth in general dental practices in Yemen. Universal Journal of Pharmaceutical Research 2019; 4(2): 1-5.

DOI: https://doi.org/10.22270/ujpr.v4i2.249

Prof. Hassan A. Al-Shamahy, Faculty of Medicine and Heath Sciences, Sana'a University, P.O. Box 775 Sana'a, Yemen. Phone: +967-770299847, E-mail: shmahe@yemen.net.ye

\section{INTRODUCTION}

Tooth extraction is one of the dental treatments which should be considered the last decision. A reduce in the number of teeth may result in poor dietary habit and decline of quality of life ${ }^{1}$. The number of extracted teeth can act as an indicator of socio-economic and oral hygiene level ${ }^{2}$. Extraction of permanent teeth is carried out for several causes including dental caries, periodontal disease, orthodontic causes, impacted teeth, failed dental treatment, prosthetic indications and other causes. An understanding of the causes why teeth are extracted is vital to enhance oral health outcomes. A large number of cross-sectional studies have investigated for tooth loss in different countries but no previous study to the current study was carried out to study the reasons for extraction teeth in Yemen except prevalence and pattern of Third Molar impaction in Sample of Yemeni Adults study which carried out last year ${ }^{3}$. Dental caries was the main cause for tooth loss worldwide $^{4-11}$, but a few studies revealed that a greater proportion of tooth extractions were due to periodontal diseases $^{11-13}$

Not enough data are available in Yemen and information on this topic is strongly required.

By detecting the main causes and predictors for tooth loss, it may be feasible to limit future extractions and emphasize the crucial role of prevention. Consequently, the purpose of this study was to inspect the causes for extraction of permanent teeth, its associations to several characteristics such as age and gender; and the best analysts for dental caries in Sana'a city, Yemen. 
Table 1: The Mean number of teeth extracted according to patient's gender and age in Sana'a University dental clinics, Sana'a city-Yemen 2017.

\begin{tabular}{lccc}
\hline Factor & $\begin{array}{c}\text { Previous extraction } \\
\text { Mean } \pm \text { SD }\end{array}$ & $\begin{array}{c}\text { Extraction on the day of } \\
\text { survey, Mean } \pm \text { SD }\end{array}$ & $\begin{array}{c}\text { Total } \\
\text { Mean } \pm \text { SD }\end{array}$ \\
\hline Gender & & & \\
\hline Male $\mathrm{n}=761(53.6 \%)^{\mathrm{a}}$ & $5.9 \pm 0.41$ & $2.1 \pm 0.1$ & $8 \pm 0.51$ \\
Female $\mathrm{n}=659(46.4 \%)$ & $4.2 \pm 0.35$ & $1.5 \pm 0.05$ & $5.7 \pm 0.4$ \\
\hline Age groups in years ${ }^{\mathrm{b}}$ & & & \\
\hline$\leq 20$ yrs $\mathrm{n}=85$ & $0.4 \pm 0.1$ & $1.5 \pm 0.1$ & $1.9 \pm 0.2$ \\
$21-30$ yrs $\mathrm{n}=274$ & $1.5 \pm 0.1$ & $1.9 \pm 0.05$ & $3.4 \pm 0.15$ \\
$31-40$ yrs $\mathrm{n}=268$ & $4.3 \pm 0.2$ & $1.6 \pm 0.05$ & $5.9 \pm 0.25$ \\
$41-50$ yrs $\mathrm{n}=327$ & $6.4 \pm 0.5$ & $2.5 \pm 0.05$ & $8.9 \pm 0.55$ \\
$51-60$ yrs $\mathrm{n}=267$ & $7.2 \pm 0.4$ & $2.6 \pm 0.1$ & $9.8 \pm 0.5$ \\
$>=61$ yrs $\mathrm{n}=199$ & $8.44 \pm 0.91$ & $2.2 \pm 0.1$ & $10.78 \pm 1.1$ \\
Total $\mathrm{n}=1420$ & $5.1 \pm .38$ & $1.82 \pm 0.07$ & $6.92 \pm 0.45$ \\
\hline \multicolumn{2}{c}{$\mathrm{a}=\mathrm{t}$ test: $\mathrm{p}<0.001 . \mathrm{b}=$ ANOVA: $\mathrm{p}<0.001}$. &
\end{tabular}

\section{SUBJECTS AND METHODS}

This cross-sectional study of following sampling was prepared on dental clinics in the Faculty of Dentistry, Sana'a University during the period from January to December 2017. A predesigned questionnaire for the study was divided into two parts: first asked for the patient's gender, age, marital status, education level, history of smoking, Qat chewing and the time of last dental visit. This part was completed by the dental assistants. The second half was finished by dentists and documented the information on previous dental extractions, tooth type and the cause for each extraction that was to be performed on the day of survey. Dentists were asked to record the code of tooth type and the main cause for each extraction. All permanent teeth extracted, including third molars, during the 12-month study period (January to December 2017) were recorded.

The causes for extraction were investigated for each tooth type in the upper and lower arch. Data were not separated into right and left quadrants as the prior surveys have revealed no differences in the rates of extraction for right and left sides of the oral cavity ${ }^{1,14}$. The data were entered and analyzed using the SPSS software (version 16.0). The extracted teeth data with normal distribution was expressed as mean and standard deviation (SD) for previous extraction and for extraction on the day of the survey. The relationships of the categorical background variables, such as age range and gender, with reasons for tooth extraction were analyzed by the 2 test, while differences in the mean number of extracted teeth per patient were analyzed with ANOVA and t test methods. A logistic regression model was used to evaluate the variables associated with reasons for tooth loss, considering tooth extraction due to caries and other causes such as caries and periodontal disease. A $p$ value of less than 0.05 was considered to be statistically significant.

\section{Ethical Consideration}

Ethical clearance for the study was taken from the Faculty of Medicine and Health Sciences Research

Review Committee. Informed Consent was taken from the volunteers before the denta NJJKl examinations.

\section{RESULTS}

Males comprised $53.6 \%$ of patients and they had more teeth extracted $(61.8 \%)$ than females $(p<0.001)$. According to Table 1, the rate of teeth extracted on the day of the survey (Mean \pm SD) per patient was $1.82 \pm 0.07 \quad(2.1 \pm 0.1$ for males and $1.5 \pm 0.05$ for females). In total, patients older than 61 years of age lost 8.44 \pm 0.91 teeth followed by age group 51-60 years lost $7.2 \pm 0.4$ teeth, more than all other age groups, as measured by the mean number of teeth lost per patient $(p<0.001)$. The highest rates of extraction on the day of survey were in patients from 51 to 60 years old (2.6 \pm 0.1 teeth). Dental caries was responsible for $69 \%$ of all extractions, while periodontal causes accounted for $28 \%$. Preprosthetic reasons (1.9\%) and other reasons $(1.14 \%)$ were less common reasons for tooth loss (Table 2). Although dental caries was responsible for most extractions in both genders, caries and periodontal disease were more common in males than females (Table 2). While caries was the leading cause for tooth extraction among young patients in $\leq 20$ years of age $(85.9 \%)$ and patients in 21-30 years of age $(85.4 \%)$. Periodontal causes were the common causes for tooth loss in patients older than 51years $(45.7 \%$ in age group $51-60$ years and $49 \%$ in age group $\geq 61$ years) $(p<0.001)$ (Table 2). The most frequently extracted teeth were mandibular first and second molars (446, $17.3 \%)$, followed by maxillary premolars $(415,16.1 \%)$, while mandibular canines were least frequently extracted $(87,3.4 \%$ ) (Table 3). Premolars, first and second molars of both jaws were the most frequently extracted teeth due to dental caries (Table 3). Additionally, periodontal problems were the main cause for the loss of all incisors in upper and lower jaws $(p<0.001)$ (Table 3$)$.

\section{DISCUSSION}

The current study indicated that in Sana'a city- Yemen, dental caries and its complications were the leading cause for extraction $(69 \%)$. Periodontal disease was the next most common reason of teeth extraction in Sana'a city in which it counted $28 \%$ of the causes (Table 2). The current finding that caries was the most common reason is in agreement with studies carried out in Iran by Jufarian and Etebarian ${ }^{15}$, in England/Wales by 
Agerholm and $\mathrm{Sidi}^{4}$, in Kuwait by Al-Shammari et al., ${ }^{5}$ in Taiwan by Chen et al., ${ }^{6}$ in Hong Kong by Corbet and Davis ${ }^{8}$, in Afghanistan by Da'ameh"; and in Brazil by Jovino-Silverira et al., ${ }^{10}$ in which the caries was the most common reason for teeth extraction. On other hand the current study results are different from findings of surveys in Italy ${ }^{16}$, Japan ${ }^{1}$, and Singapore ${ }^{17}$ which they showed that both caries and periodontal disease were almost equally important causes for tooth loss. In addition, current study results are different from studies in Jordan ${ }^{11}$ and Canada ${ }^{12,13}$ which demonstrated that the main cause of tooth loss was periodontal disease. Besides, Singapore $^{17}$ and Germany $^{18}$ had a lower percentage of dental caries compared to current study and many former studies $^{3,5,19,20}$. These differences may be attributed to socio-economic factors, diet, level of dental awareness on top of water fluoridation in these countries ${ }^{17,18}$.

Table 2: Reasons for extraction teeth in Sana'a University dental clinics, Sana'a city-Yemen 2017.

\begin{tabular}{lccccc}
\hline Factor & Dental caries & $\begin{array}{c}\text { Periodontal } \\
\text { problem }\end{array}$ & $\begin{array}{c}\text { Pre-prosthetic } \\
\text { reasons }\end{array}$ & $\begin{array}{c}\text { Other } \\
\text { reasons }\end{array}$ & Total \\
\cline { 2 - 6 } & No (\%) & No (\%) & No (\%) & No (\%) & No (\%) \\
\hline Gender & & & & & \\
\hline Male $n=761$ & $1020(63.8 \%)$ & $516(32.3 \%)$ & $38(2.4 \%)$ & $24(1.5 \%)$ & $1598(61.8 \%)$ \\
Female $\mathrm{n}=659$ & $762(77.2 \%)$ & $209(21.2 \%)$ & $11(1.1 \%)$ & $5(0.5 \%)$ & $987(38.2 \%)$ \\
Age groups in years & & & & & \\
\hline$\leq 20$ yrs $\mathrm{n}=85$ & $133(85.9 \%)$ & $11(7.1 \%)$ & $0(0.0 \%)$ & $11(7.1 \%)$ & $155(6 \%)$ \\
$21-30$ yrs $\mathrm{n}=274$ & $425(85.4 \%)$ & $64(12.8 \%)$ & $3(0.36 \%)$ & $7(1.5 \%)$ & $499(19.3 \%)$ \\
$31-40$ yrs $\mathrm{n}=268$ & $403(82.8 \%)$ & $84(17.2 \%)$ & $0(0.0 \%)$ & $0(0.0 \%)$ & $487(18.8 \%)$ \\
$41-50$ yrs $\mathrm{n}=327$ & $400(67.2 \%)$ & $164(27.5 \%)$ & $20(3.4 \%)$ & $11(1.8 \%)$ & $596(23.1 \%)$ \\
$51-60$ yrs $\mathrm{n}=267$ & $260(53.6 \%)$ & $222(45.7 \%)$ & $4(0.62 \%)$ & $0(0.0 \%)$ & $486(18.8 \%)$ \\
$\geq 61$ yrs $\mathrm{n}=199$ & $160(44.2 \%)$ & $180(49.7 \%)$ & $22(6.1 \%)$ & $0(0.0 \%)$ & $362(14 \%)$ \\
Total $\mathrm{n}=1420$ & $1782(69 \%)$ & $725(28 \%)$ & $49(1.9 \%)$ & $29(1.14 \%)$ & $2585(100 \%)$ \\
\hline
\end{tabular}

$\mathrm{a}=2$ test: $\mathrm{p}<0.001, \mathrm{~b}=$ Other reasons include: failure of previous dental treatment, financial problems, trauma esthetic reasons, Qat chewing and others.

Table 3: Reasons for extraction by tooth type in Sana'a University dental clinics, Sana'a city-Yemen 2017.

\begin{tabular}{lccccc}
\hline & Dental caries & $\begin{array}{c}\text { Periodontal } \\
\text { problem }\end{array}$ & $\begin{array}{c}\text { Pre-prosthetic } \\
\text { reasons }\end{array}$ & $\begin{array}{c}\text { Other } \\
\text { reasons }\end{array}$ & Total \\
\hline $\begin{array}{l}\text { Maxillary arch } \\
\text { Incisors n=220 }\end{array}$ & $89(40.5 \%)$ & $106(47.9 \%)$ & $13(5.8 \%)$ & $12(5.8 \%)$ & $220(8.5 \%)$ \\
Canines n=145 & $82(56.3 \%)$ & $50(34.5 \%)$ & $4(2.5 \%)$ & $9(6.3 \%)$ & $145(5.6 \%)$ \\
Premolars n=415 & $322(77.6 \%)$ & $82(15.6 \%)$ & $9(2.2 \%)$ & $2(0.44 \%)$ & $415(16.1 \%)$ \\
$\begin{array}{l}\text { First And Second } \\
\text { molars n=350 }\end{array}$ & $271(77.6 \%)$ & $73(20.8 \%)$ & $6(1.7 \%)$ & $0(0.0 \%)$ & $350(13.5 \%)$ \\
Third molar n=184 & $147(80.2 \%)$ & $35(18.8 \%)$ & $2(1 \%)$ & $0(0.0 \%)$ & $184(7.1 \%)$ \\
Mandibular arch & & & & & \\
Incisors n =166 & $66(39.7 \%)$ & $98(59.3 \%)$ & $2(1.1 \%)$ & $0(0.0 \%)$ & $166(6.4 \%)$ \\
Canines n =87 & $43(49.4 \%)$ & $38(43.8 \%)$ & $4(4.5 \%)$ & $2(2.1 \%)$ & $87(3.4 \%)$ \\
Premolars n=346 & $238(68.9 \%)$ & $104(30 \%)$ & $4(1.1 \%)$ & $0(0.0 \%)$ & $346(13.4 \%)$ \\
First And Second & $344(77.1 \%)$ & $95(21.2 \%)$ & $5(1.2 \%)$ & $2(0.4 \%)$ & $446(17.3 \%)$ \\
molars n=446 & & & & & \\
Third molar n=226 & $180(79.8 \%)$ & $44(19.4 \%)$ & 0 & $2(0.8 \%)$ & $226(8.7 \%)$ \\
Total n=1420 & $1782(69 \%)$ & $725(28 \%)$ & $49(1.9 \%)$ & $29(1.14 \%)$ & $2585(100 \%)$ \\
\hline
\end{tabular}

In the current study, most patients whose teeth were extracted were 21-61 years old age groups, while extraction in younger patients $(\leq 20$ years) accounted for only $6 \%$ of all teeth loss. Even if, $45.7 \%$ and $49.7 \%$ of teeth extracted for periodontal disease were in patients over 50 years of age (Table 2); caries was still the major cause for extraction even in elderly patients, but to a less degree than in younger ones. This result was also reported by Thomas and AlMaqdassy $^{21}$. Nevertheless, current study, as previously mentioned, is not in agreement with studies where periodontal disease was the major cause of extraction in patients over 40 years old of, $^{2,13,16,17}$. It may be that extractions caused by caries are occurring later in the disease process, possibly following initial efforts to treat the tooth. In other words, if more teeth are restored rather than extracted, then extractions would be postponed to an older age group. Consequently, the continuing high frequency of extraction for caries may indicate an increase in restorations prior to extraction rather than high incidence of caries in older people.

In this survey, the mean number of teeth extracted per patient was 1.82 , higher than the 1.26 reported by Angelillo et al., ${ }^{16}$ in Italy and the 1.3 found by Corbet and Davies ${ }^{8}$ in Hong Kong, but lower than the 2.42 reported by Chrysanthakopoulos ${ }^{2}$ in a study in Greece and the 2.3 found by Murray et al., ${ }^{13}$ in Canada. These dissimilarities are at least in part attributed to different response rates, methodological differences plus the age of the population sample. Therefore, comparison of tooth extraction data between different countries is loaded with difficulty. When considering all the teeth patients had extracted until the day of examination, the mean number of tooth loss in patients over 60 was 8.4, the highest among all age groups. This finding substantiated the evidence for increasing prevalence of tooth loss with increasing age ${ }^{16,22}$. In the current study, the most repeatedly extracted teeth were mandibular first and second molars (446, 17.3\%), followed by 
maxillary premolars $(415,16.1 \%)$ (Table 3$)$, while in studies by Thomas and Al-Maqdassy ${ }^{21}$ and Marcus et al., ${ }^{22}$ in USA, third molars were the most frequently extracted teeth, and this is mainly for impaction reasons ${ }^{\mathbf{4}, 6,16}$, while first and second molars in these studies were mainly extracted due to dental caries similar to current results ${ }^{4,16,18,20}$. In the current study periodontal disease was the principal cause of the tooth loss in incisors (maxillary $=47.9 \%$, mandibular $=59.3 \%$, (Table 3) similar to that reported by Corbet and Davies in Hong $\mathrm{Kong}^{8}$; and Morita et al., in Japan which periodontal disease was the principal cause of the tooth loss in incisors. In the current study teeth extracted for pre-prosthetic reasons were mainly maxillary incisors (5.5\%) (Table 3), different from that reported by Murray et al., ${ }^{13}$ in Canada and McCaul et al., ${ }^{14}$ in Scotland in which first and second premolars and teeth extracted for the same reasons were mainly first and second premolars. A likely reason for the high periodontal extraction in anterior teeth is that they are less susceptible to caries, preserved longer in the mouth, and then may be subjected to the risk of periodontal diseases ${ }^{2,5,17,19}$.

In the current study, males comprised $53.6 \%$ of patients and they had more teeth extracted (61.8\%) than females ( $p<0.001)$. According to Table 1 , the rate of teeth extracted on the day of the survey was $2.1 \pm 0.1$ in males higher than that of $1.5 \pm 0.05$ in females. Multiple tooth loss was higher in men might be due to their lack of interest in spending more time on complicated restorative treatments rather than extractions as it has been confirmed by the finding of Da'ameh in Afghanistan'. There was proportionally more extraction for caries in women than in men in the current study (77.2\% Versus $63.9 \%$ respectively) (Table 2), this finding which is in disagreement with other studies $^{10,14,19,23}$ While caries in the current study were the main causes of tooth loss in females, males lost more teeth due to caries and periodontal disease. The second finding was similar to previous investigations ${ }^{2,5,24,25}$. What is more, male gender has been reported as a risk indicator for periodontal disease severity ${ }^{2,5,26}$. Finally; studies on tooth loss have generally discussed very few factors associated with missing teeth ${ }^{10,27,28}$. In this study, several predictors for tooth loss due to caries were considered. Patients' age had a significant association with dental caries, while a study by Jovino-Silveria et al., in Brazil ${ }^{10}$ showed age as the best predictor for tooth loss due to periodontal disease.

\section{CONCLUSION}

The outcomes of this survey revealed that dental caries and periodontal diseases were the most important causes for tooth extraction in Sana'a city, Yemen. The best predictors for tooth loss due to caries were age and gender, tooth type and having had a previous extraction. What's more, strategies for efficient ways of screening for periodontal disease, in particular for middle aged people, might be requisite. Future studies could be alert on changes in causes for dental extraction in a time trend to determine whether or not their relative importance has changed. Intervention studies could also be conducted with the available data and more surveys could be carried out to compare extraction patterns between public and private dental practices.

\section{AUTHOR'S CONTRIBUTION}

The manuscript was carried out, written, and approved in collaboration with all authors.

\section{ACKNOWLEDGEMENTS}

The authors extend their thanks and appreciation to the Sana'a University, Sana'a, Yemen to provide necessary facilities for this work.

\section{CONFLICT OF INTEREST}

No conflict of interest associated with this work.

\section{REFERENCES}

1. Aida J, Ando Y, Akhter R, Aoyama H, Masui M, Morita M. Reasons for permanent tooth extractions in Japan. J Epidemiol 2006; 16:214-219. https://doi.org/10.2188/jea.16.214

2. Chrysanthakopoulos NA. Reasons for extraction of permanent teeth in Greece: a five-year follow-up study. Int Dent J 2011; 61:19-24. https://doi.org/10.1111/j.1875-595X.2011.00004.x

3. Alhadi Y, Al-Shamahy HA, Aldilami A, Al-Hamzy M, AlHaddad KA, et al. Prevalence and pattern of third molar impaction in sample of Yemeni adults. On J Dent Oral Health 2019; 1(5):1-4.

https://doi.org/10.33552/OJDOH.2019.01.000523

4. Agerholm DM, Sidi AD: Reasons given for extraction of permanent teeth by general dental practitioners in England and Wales. Br Dent J 1988; 164:345-348.

https://doi.org/10.1038/sj.bdj.4806451

5. Al-Shammari KF, Al-Ansari JM, Al-Melh MA, Al-Khabbaz AK: Reasons for tooth extraction in Kuwait. Med Princ Pract 2006; 15:417-422.https://doi.org/10.1159/000095486

6. Chen SC, Chueh LH, Hsiao CK, Wu HP, Chiang CP: First untoward events and reasons for tooth extraction after nonsurgical endodontic treatment in Taiwan. J Endod 2008; 34:671-674.https://doi.org/10.1016/j.joen.2008.03.016

7. Chestnutt IG, Binnie VI, Taylor MM: Reasons for tooth extraction in Scotland. J Dent 2000; 28:295-297. https://doi.org/10.1016/S0300-5712(99)00069-X

8. Corbet EF, Davies WI: Reasons given for tooth extraction in Hong Kong. Community Dent Health 1991; 8:121-130. PMID: 1878791

9. Da'ameh D: Reasons for permanent tooth extraction in the North of Afghanistan. J Dent 2006; 34:48-51 https://doi.org/10.1016/j.jdent.2005.02.009

10. Jovino-Silveira RC, Caldas AF Jr, de Souza EH, Gusmão ES: Primary reason for tooth extraction in a Brazilian adult population. Oral Health Prev Dent 2005; 3:151-157. https://doi.org/10.4103/0972-124X.170852

11. Haddad I, Haddadin K, Jebrin S, Ma'Ani M, Yassin O: Reasons for extraction of permanent teeth in Jordan. Int Dent J 1999; 49:343-346. https://doi.org/10.1111/j.1875-595X.1999.tb00535.x

12. Matthews DC, Smith CG, Hanscom SL: Tooth loss in periodontal patients. J Can Dent Assoc 2001; 67:207-210.

13. Murray H, Locker D, Kay EJ: Patterns of and reasons for tooth extractions in general dental practice in Ontario, Canada. Community Dent Oral Epidemiol 1996; 24:196-200. https://doi.org/10.1111/j.1600-0528.1996.tb00841.x

14. McCaul LK, Jenkins WMM, Kay EJ. The reasons for the extraction of various tooth types in Scotland: a 15-year follow up. J Dent 2001; 29:401-407. https://doi.org/10.1016/s0300-5712(01)00036-7 
15. Jafarian $\mathrm{M}$ and Etebarian A. Reasons for extraction of permanent teeth in general dental practices in Tehran, Iran. Med Princ Pract 2013; 22:239-244. https://doi.org/10.1159/000345979

16. Angelillo IF, Nobile CGA, Pavia M: Survey of reasons for extraction of permanent teeth in Italy. Community Dent Oral Epidemiol 1996; 24:336-340. https://doi.org/10.1111/j.1600-0528.1996.tb00872.x

17. Ong G, Yeo JF, Bhole S: A survey of reasons for extraction of permanent teeth in Singapore. Community Dent Oral Epidemiol 1996; 24:124-127.

https://doi.org/10.1111/j.1600-0528.1996.tb00828.x

18. Reich E, Hiller KA: Reasons for tooth extraction in the western states of Germany. Community Dent Oral Epidemiol $1993 ; 21: 379-383$.

https://doi.org/10.1111/j.1600-0528.1993.tb01103.x

19. Kay EJ, Blinkhorn AS: The reasons underlying the extraction of teeth in Scotland. Br Dent J 1986; 160:287-290. https://doi.org/10.1038/sj.bdj.4805837

20. Morita M, Kimura T, Kanegae M, Ishikawa A, Watanabe T: Reasons for extraction of permanent teeth in Japan. Community Dent Oral Epidemiol 1994; 22:303-306. https://doi.org/10.1111/j.1600-0528.1994.tb02056.x

21. Thomas S, Al-Maqdassy SE: Causes and pattern of tooth mortality among adult patients in a teaching dental hospital. Ibnosina J Med BS 2010; 2:160-167. https://doi.org/10.1517/14740338.2013.827660
22. Marcus SE, Kaste LM, Brown LJ: Prevalence and demographic correlates of tooth loss among the elderly in the United States. Spec Care Dentist 1994; 14:123-127. https://doi.org/10.1111/j.1754-4505.1994.tb01117.x

23. Caldas AF Jr, Marcenes W, Sheiham A: Reasons for tooth extraction in a Brazilian population. Int Dent J 2000; 50:267273. https://doi.org/10.1111/j.1875-595X.2000.tb00564.x

24. Fardal, Johannessen AC, Linden GJ: Tooth loss during maintenance following periodontal treatment in a periodontal practice in Norway. J Clin Periodontol 2004; 31:550-555. https://doi.org/10.1111/j.1600-051X.2004.00519.x

25. Locker D, Ford J, Leake J: Incidence of and risk factors for tooth loss in a population of older Canadians. J Dent Res 1996; 75:783-789. https://doi.org/10.1177/00220345960750020801

26. Grossi S, Genco R, Machtei E, Ho A, Koch G, Dunford R, Zambor JJ, Hausmann E: Assessment of risk for periodontal disease. 2. Risk indicators for alveolar bone loss. J Periodontol 1995; 66:23-29.

https://doi.org/10.1902/jop.1995.66.1.23

27. Klock KS: Patients' perceptions of the decision-making process leading to extraction of permanent teeth in Norway. Community Dent Oral Epidemiol 1995; 23:165-169. https://doi.org/10.1111/j.1600-0528.1995.tb00222.x

28. Worthington H, Clarkson J, Davies R: Extraction of teeth over 5 years in regularly attending adults. Community Dent Oral Epidemiol 1999; 27:187.

https://doi.org/10.1111/j.1600-0528.1999.tb02009.x 